\title{
Effects of Coumestrol Treatment on Spermatogenesis in Dogs
}

\author{
Rajesh Kumar', A.K. Sharma ${ }^{2}$, Gyan Singh ${ }^{3 *}$ and Ravi Dutt ${ }^{2}$ \\ ${ }^{1}$ ICAR-Central Institute for Research on Buffaloes, Hisar-125001, Haryana, India \\ ${ }^{2}$ Department of Veterinary Gynaecology and Obstetrics, LUVAS, Hisar - 125 004, \\ Haryana, India \\ ${ }^{3}$ Veterinary Clinical Complex, LUVAS, Hisar -125 004, Haryana, India \\ *Corresponding author
}

\section{A B S T R A C T}

\section{Keywords}

Coumestrol, Dogs,

Histology,

Spermatogenesis, Sterilization

Article Info

Accepted:

24 January 2018

Available Online:

10 February 2018
The establishment of safe and effective fertility inhibitors for dogs must also be matched by evidence that non-surgical fertility control is an efficient, humane, and socially acceptable alternative to surgical sterilization for managing over abundant populations of dogs and their impact on human interests. The present study was undertaken to study the contraceptive effects of coumestrol in adult male dogs. Experimental group I was given $300 \mu \mathrm{g}$ coumestrol dissolved in di-methyl sulfoxide orally in the commercial dog treats, on days $0,7,14,21$ and 28. Control group II was given DMSO alone as per above schedule. One week after the end of treatment period, dogs were anaesthetized with xylazine (2.0mg/kg B. weight) and ketamine $\mathrm{HCl}(10 \mathrm{mg} / \mathrm{kg} \mathrm{B}$. weight). Testicles were removed and efferent ductules were collected and fixed in Bouin's fixatives. Tissues were dehydrated in methanol and cleared in xylene, and then paraffin blocks were prepared. Sections were cut at 5-7 $\mu$ and stained with Harris-hematoxylin and Eosin. Histological examination of the testicular tissues revealed normal germinal epithelium. Therefore, it was concluded that oral feeding of $300 \mu \mathrm{g}$ coumestrol did not have any adverse effect on male dog fertility.

\section{Introduction}

The global dog population is estimated to be around 700 million (Hughes and Macdonald, 2013). In developed countries, rabies is present mainly in wild animal hosts, while in developing countries stray animals play the important role in transmission of the disease. About $75 \%$ of dogs worldwide are free to roam and reproduce, thus creating locally overabundant populations. Problems caused by roaming dogs include diseases transmitted to livestock and humans, predation on livestock, attacks on humans, road traffic accidents, and nuisance behavior (Macpherson et al., 2013). In Bangalore (India), 64\% of dog bites were associated with stray dogs (Sudarshan et al., 2001). Among the zoonoses, rabies is of particular concern for humans and livestock. Dogs are responsible for $>90 \%$ of the estimated 55,000 human deaths and for the millions of people that each year receive postexposure prophylaxis following a bite (Knobel et al., 2005). The population control of these unowned feral dogs cannot be done by surgical method alone. Because this method is 
expensive, time consuming, require expertise staff, boarding and post-surgical care. Development of non-surgical methods of sterilization will provide an alternative strategy, particularly in areas where surgical initiative may not be feasible.

Nowadays, the use of some phytoestrogens is being investigated for reproductive control (Serrano et al., 2007). Coumestrol is one of the phytoestrogen found in high concentration in soya germs, clover and alfalfa sprout (Murkis et al., 1998). It decreases the reproductive performance of the bovine and ovine (Adams, 1995), increases apoptosis in seminiferous tubules in rats (Atanassova et al., 2000), decreases sperm maturation in cattle (Pike et al., 1999). Coumestrol feeding to vampire bats at the dose rate of $200 \mu \mathrm{g}$ for one month causes ultra-structural changes like absence of Leydig's cells and mature spermatozoa in the lumen of seminiferous tubules in the testis (Serrano et al., 2007). Also in dogs coumestrol feeding at dose rate of $300 \mu \mathrm{g}$ on days $0,7,14,21$ and 28 , revealed absence of mature tailed spermatozoa in the lumen of tubuli with increased abnormal spermatozoa and oligospermiain the ejaculation of dogs (Perez-Rivero et al., 2009). Keeping these findings in mind, present study was planned to investigate the contraceptive effects of coumestrol in dogs.

\section{Materials and Methods}

The study was conducted in Department of Veterinary Gynaecology and Obstetrics, College of Veterinary Sciences, Lala Lajpat Rai University of Veterinary and Animal Sciences (LUVAS), Hisar. For experimental studies, permission from Institutional Animal Ethics Committee was taken. Ten healthy nondescript male dogs of 2-4 years of age were selected and kept for study till completion of experiment. Dogs were randomly divided into two groups. Experimental group I $(\mathrm{n}=5)$ was given $300 \mu \mathrm{g}$ coumestrol dissolved in dimethyl sulfoxide (DMSO) orally in the commercial dog treats, on days $0,7,14,21$ and 28. Control group II $(\mathrm{n}=5)$ was given DMSO alone as per above schedule. One week after the end of treatment period, dogs were anaesthetized with an intra-muscular injection of xylazine $(2.0 \mathrm{mg} / \mathrm{kg}$ B. weight) and ketamine $\mathrm{HCl}(10 \mathrm{mg} / \mathrm{kg} \mathrm{B}$. weight). Testicles were removed and efferent ductules were collected and fixed in Bouin's fixatives for histology. Tissues were dehydrated in methanol and cleared in xylene, and then paraffin blocks were prepared. Sections were cut at 5-7 $\mu$ and stained with Harrishematoxylin and Eosin ( $\mathrm{H} \& \mathrm{E})$.

\section{Results and Discussion}

Histological examination of the testicular tissues revealed normal germinal epithelium in treatment and control groups. Spermatogonia, primary spermatocytes, secondary spermatocytes and spermatids were normal in seminiferous tubules. All seminiferous tubules were showing active spermatogenesis. All stages of seminiferous epithelial cycle were present in both experimental and control group (Fig. 1-6). No significant effect was seen on spermatogenesis in the coumestrol treated group. Histological examination of the testicular tissues revealed normal germinal epithelium in treatment and control groups. Spermatogonia, primary spermatocytes, secondary spermatocytes and spermatids were normal in seminiferous tubules. All the seminiferous tubules were showing active spermatogenesis. Eight stages of seminiferous epithelial cycle were present. It is assumed that, coumestrol has acted as an estrogen agonist because of low doses used in this study through which it could not affect fertility. From the present study, it was concluded that oral feeding of $300 \mu \mathrm{g}$ coumestrol to the dogs did not cause any adverse effects on spermatogenesis. 
Fig.1 Group I: Seminiferous epithelial cycle, Stage I X 400

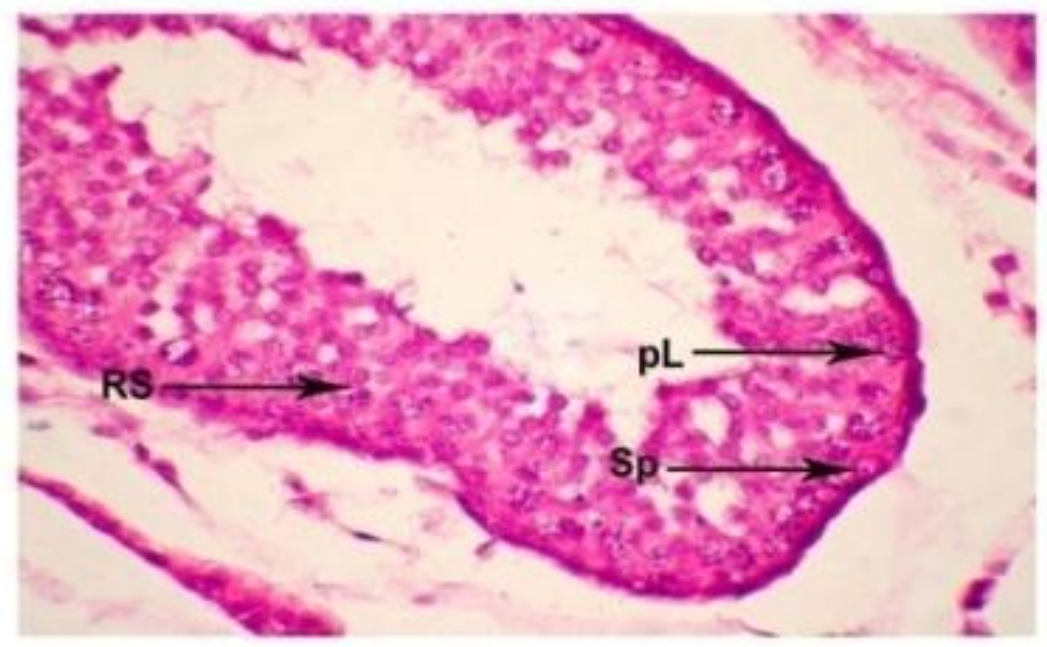

Fig.2 Group I: Seminiferous epithelial cycle, Stage III x 400

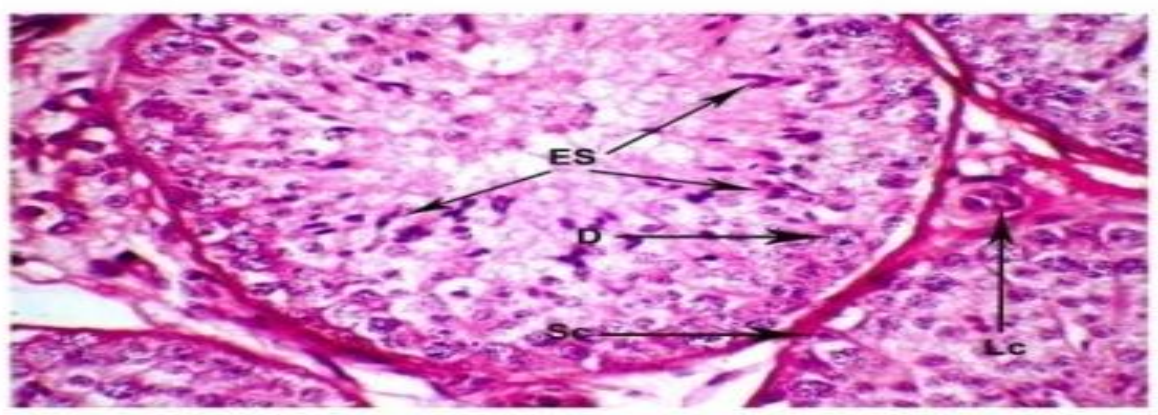

Fig.3 Group I: Seminiferous epithelial cycle, Stage VIII x 400

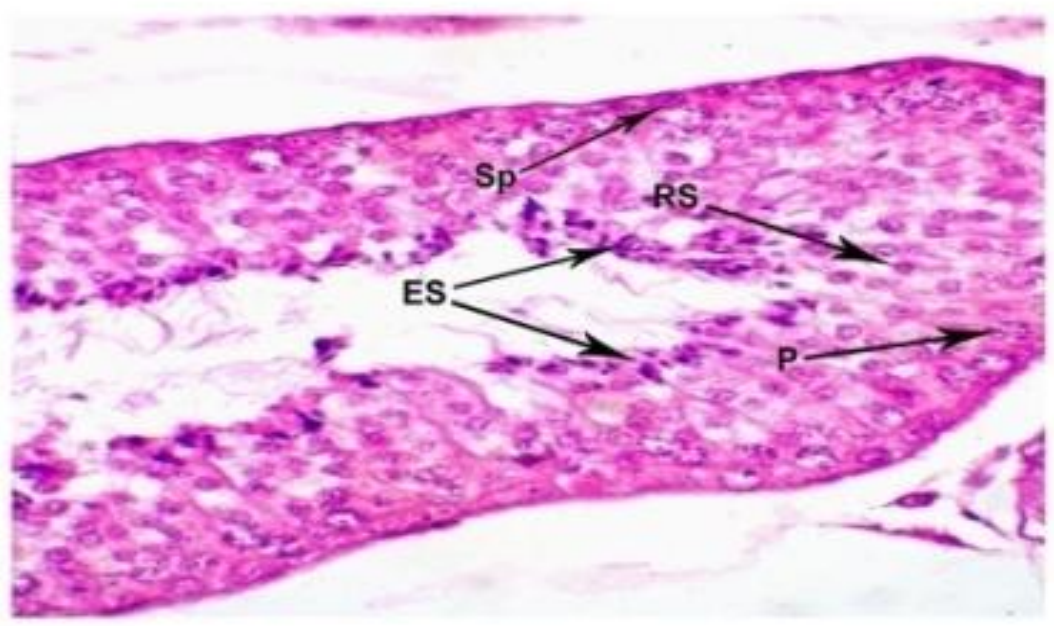


Fig.4 Group II: Seminiferous epithelial cycle, Stage II x 400

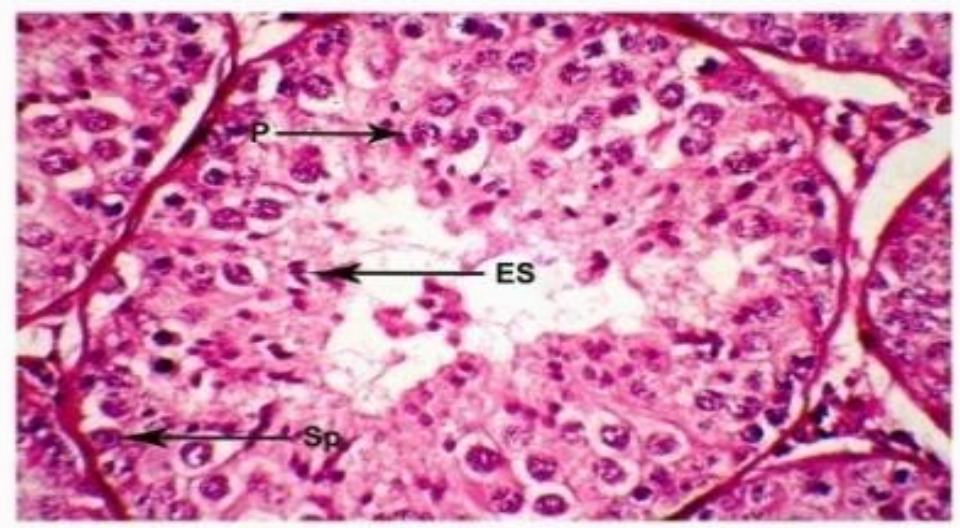

Fig.5 Group I: Seminiferous epithelial cycle, Stage III x 400

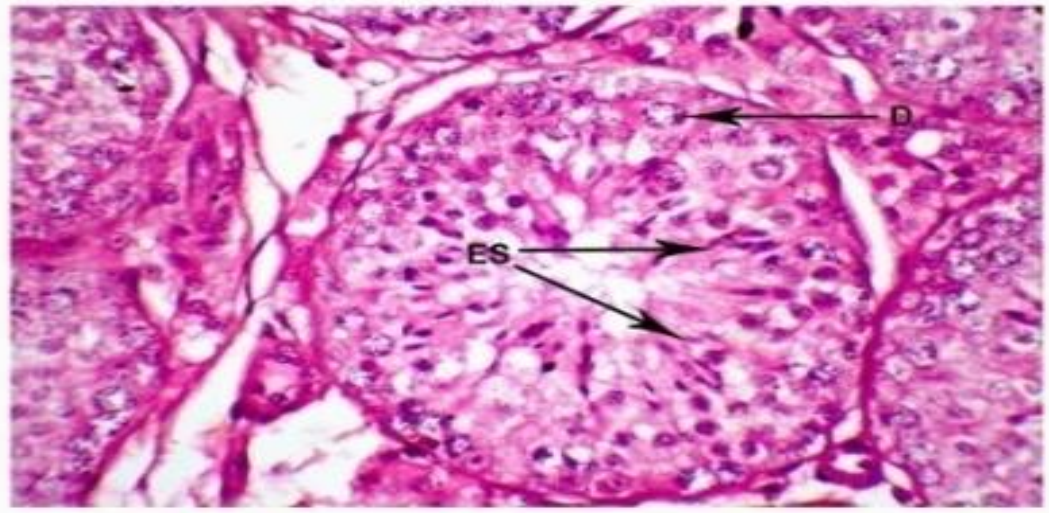

Fig.6 Group II: Seminiferous epithelial cycle, Stage VIII x 400

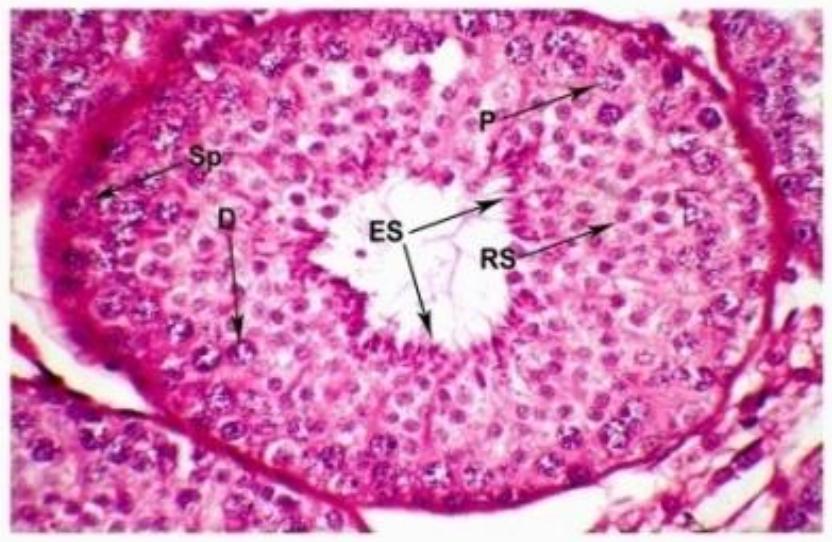

Cross section of the seminiferous tubules showing stages of seminiferous epithelial cycle (Hematoxylin and Eosin stain $\times$ 400): Treatment group (Fig. 1-3) and control group (Fig. 4-6) Spermatogonia (Sp), Preleptotene spermatocytes (pL), Round spermatids (RS), Diplotene spermatocytes (D), elongated spermatids (ES), Pachytene spermatocytes (P), Sertoli cells (Sc) and Leydig cells (Lc). 
Coumestrol does not affect male fertility at all as it doesn't bind with estrogen receptors (Rahhal and Jone, 2011). So, at this dose rate, this compound cannot be used for population control of stray dogs, however, coumestrol therapy in pre-pubertal dogs or at slight higher dose rate with repeated administrations can also be tried in further studies.

From the present study, it was concluded that oral feeding of $300 \mu \mathrm{g}$ coumestrol to the dogs did not cause any adverse effects, spermatogenesis, and seminiferous epithelial cycle.

\section{Acknowledgment}

The authors would like to thank the Head of the Department of Veterinary Gynaecology and Obstetrics, LUVAS, Hisar, Haryana, India for generation of fund for the present study.

\section{References}

Adam, N.R., 1995. Detection of the effects of phytoestrogens on sheep and cattle. J. Anim. Sci., 73: 1509-1515.

Atanassova, N., McKinnell, C., Turner, K. J., Walker, M., Fisher, J.S., Morley, M., Millar, M.R., Groome, N. P. and Sharpe, R. M., 2000. Comparative effects of neonatal exposure of male rats to potent and weak (environmental) estrogens on spermatogenesis at puberty and the relationship to adult testis size and fertility: evidence for stimulatory effects of low estrogen levels. Endocrin, 141:3898-3907.

Hughes, J. and Macdonald, D.W. 2013. A review of the interactions between freeroaming domestic dogs and wildlife. Biol. Conserv., 157: 341-51.
Knobel, D.L., Cleaveland, S., Coleman, P.G., Fèvre, E.M., Meltzer, M.I. and Miranda, M.E. 2005. Re-evaluating the burden of rabies in Africa and Asia. Bull WHO. 83:360-8.

Macpherson, C.N.L, Meslin, F.X. and Wandeler, A.I. 2013. Dogs, zoonoses and public health. Second edition. Wallingford, UK: CABI International.

Murkis, A.L., Wilcox, G. and Davis, R.S., 1998. Phytoestrogens. J. Clin. Endocrinol. Metab., 83:297-303.

Perez-Rivero, J. J., Martinez-Maya, J. J., PerezMartinez, M., Aguilar-Setien, A., GarciaSuarez, M. D. and Serrano, H., 2009. Phytoestrogen treatment induces testis alterations in dogs. Potential use in population control. Vet. Res. Commun., 33: 87-95.

Pike, A. C. W., Brzozowski, A. M., Hybbard, R. E., Bonn, T., Thorsell, A. G., Engstrom, O., Ljunggren, J., Gustafsson, J.A., and Carlquist, M., 1999. Structure of the ligand binding domain of oestrogen receptor beta in the presence of partial agonist and full antagonist. EMBO. J., 18:4608-4618.

Rahhal, G. and John, P. S., 2011. A fluorescence-based investigation on estrogen ligand complexes. National conference on undergraduate research, State University of New York.

Serrano, H., Perez-Rivero, J. J., Aguilar- Setien, A., Paz - de, O. and Villa- Godoy, A., 2007. Vampire bat reproductive control by a naturally occurring Phytoestrogen. Reprod. Fert. Develop, 19: 470-72.

Sudarshan, M.K., Mahendra, B.J. and Narayan, D.H. 2001. A community survey of dog bites, anti-rabies treatment, rabies and dog population management in Bangalore city. J Comm. Dis., 33:245-51.

\section{How to cite this article:}

Rajesh Kumar, A.K. Sharma, Gyan Singh and Ravi Dutt. 2018. Effects of Coumestrol Treatment on Spermatogenesis in Dogs. Int.J.Curr.Microbiol.App.Sci. 7(02): 2606-2610.

doi: https://doi.org/10.20546/ijcmas.2018.702.317 